Case Report

\title{
Sinus of Valsalva Fistula to the Right Ventricle along with Coronary Artery Fistula to the Pulmonary Artery in a Young Native American Female
}

\author{
Sarika Desai, ${ }^{1}$ Erica Flores, ${ }^{2}$ Akil Loli, ${ }^{3}$ and Peter Maki $^{3}$ \\ ${ }^{1}$ Banner Good Samaritan Medical Center, USA \\ ${ }^{2}$ Cardiology Fellowship Office, Banner Good Samaritan Medical Center, 1111 East McDowell Road, Phoenix, AZ 85006, USA \\ ${ }^{3}$ Department of Cardiology, Biltmore Cardiology/Banner Good Samaritan Medical Center, USA
}

Correspondence should be addressed to Erica Flores; eflores21@gmail.com

Received 23 August 2013; Accepted 9 October 2013

Academic Editors: G. Minardi and K. Shimada

Copyright (C) 2013 Sarika Desai et al. This is an open access article distributed under the Creative Commons Attribution License, which permits unrestricted use, distribution, and reproduction in any medium, provided the original work is properly cited.

\begin{abstract}
Sinus of Valsalva aneurysm is a rare condition and associated with a high rate of mortality if rupture occurs. The aneurysms are rarely diagnosed until rupture occurs. This case describes a young Native American female whose only symptom was intermittent chest pain prior to the detection of the aneurysm along with a small ventricular septal defect. The patient was also found to have a coexisting coronary artery fistula, and it is rare phenomenon to have these coexisting anomalies. The anomalies were demonstrated on both cardiac computed tomography and coronary angiography. The patient underwent surgical closure of both anomalies, which is the recommended treatment to avoid future complications.
\end{abstract}

\section{Introduction}

Sinus of Valsalva fistulas was first described in 1839. The incidence of sinus of Valsalva fistulas ranges considerably in previously conducted studies form $0.14 \%$ to $0.96 \%$ [1-3]. In one study by Takach and colleagues, the most common site of origin was the right coronary sinus with rupture into the right ventricle. Ventricular septal defects were an associated finding in $11.6 \%$ of cases, which was a finding in our patient. The absolute indications for surgical intervention in a ruptured fistula include right ventricular outflow obstruction, infection, arrhythmias, or coronary artery obstruction [4]. However, the literature is less definitive regarding the optimal management for asymptomatic, nonruptured fistulas.

\section{Case Presentation}

A 32-year-old Native American female was referred to cardiology for a newly diagnosed heart murmur and a history of previously diagnosed congenital heart disease. The patient reported atypical chest pain intermittently upon awakening but denies any palpitations or dyspnea. The patient had been diagnosed with a cardiac abnormality and murmur at birth, but she believed the murmur and abnormality had resolved. The patient was previously diagnosed with mild developmental delay, hyperthyroidism, and asthma. She lives with her parents and denies any alcohol or drug use. There was no family history of congenital heart disease. Clinical examination revealed a 3/6 systolic murmur at the left lower sternal border radiating to the apex. A continuous, highpitched, and diastolic murmur was also were noted at the left sternal border.

The transthoracic echocardiogram showed an intracardiac shunt from the right coronary sinus of Valsalva to the right atrium creating inward movement towards the right atrium of the tricuspid valve during systole. The echocardiogram also revealed mild to moderate tricuspid regurgitation, right atrial enlargement, and right and left ventricles with normal size and function. Cardiac computed tomography angiography was obtained for better anatomical delineation of the abnormality, which showed presumably no evidence of coronary artery obstruction and a small ventricular septal defect in the mid-septum. The sinuses of Valsalva were found to be prominent with communication between the right 


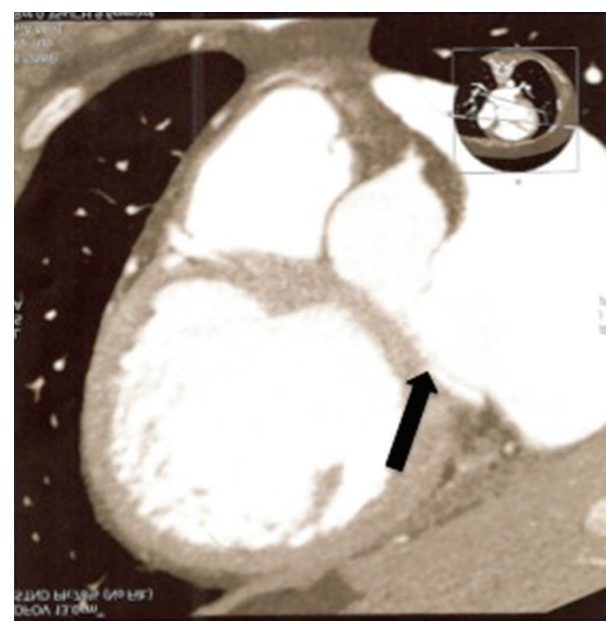

FIGURE 1: Cardiac CT demonstrating aortic right ventricular fistula.

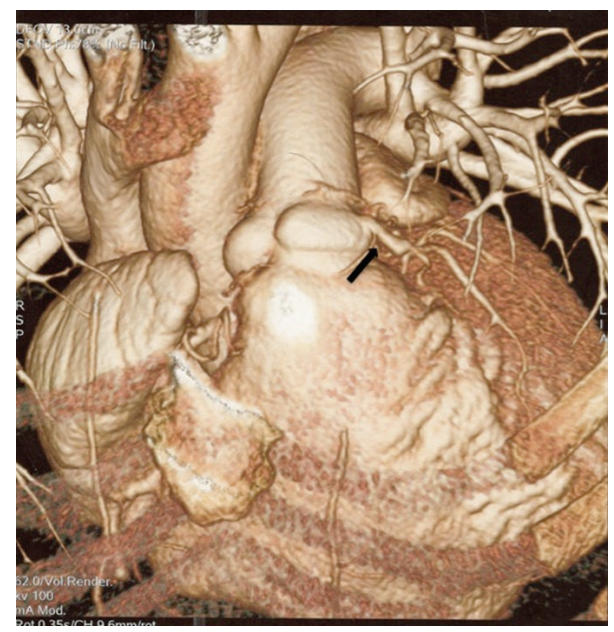

FIGURE 2: Cardiac CT demonstrating aortic right ventricular fistula.

coronary sinus at its base and the right ventricle (Figures 1 and 2). The computed tomography of the chest was unremarkable.

The patient underwent a right and left cardiac catheterization with aortography. The coronary angiography demonstrated a fistula between the proximal circumflex artery and the pulmonary artery (PA) (Figure 3). Left ventriculography was normal. Aortic angiography showed passage of contrast between the aortic root and right heart chambers (Figure 4). There was evidence of a large left to right shunt with a Qp : Qs ratio of $2.7: 1$.

After testing was completed, the patient was ultimately found to have a sinus of Valsalva aneurysm of the right coronary sinus, an aorto-right ventricular fistula, a proximal circumflex artery to pulmonary artery fistula, and a small ventricular septal defect. She was sent for consultation with cardiothoracic surgery and surgical closure was recommended. She underwent repair of the sinus of Valsalva aneurysm with a Dacron graft, closure of the aorto-right ventricular fistula with a CorMatrix patch, reimplantation of

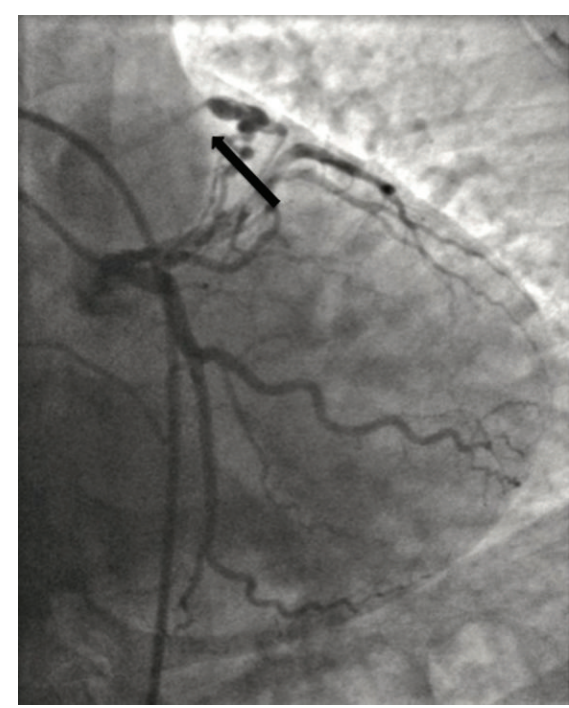

FIGURE 3: Coronary angiography demonstrating fistula between the proximal circumflex artery and pulmonary artery.

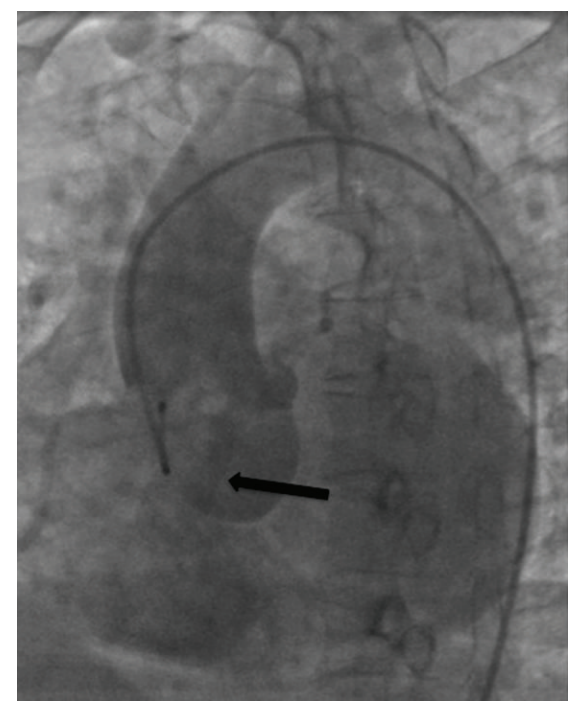

FIGURE 4: Aortic angiography demonstrating aortic right ventricular fistula.

the right coronary artery, ligation of the circumflex arteryPA fistula, and tricuspid valve repair with an Edwards annuloplasty ring. The patient had an unremarkable postop course and was discharged home.

\section{Discussion}

Fistulas of the coronary sinus are rare. The aortic right ventricular fistula falls within abnormal vascular connections of the aorta named aortocameral fistulas. The diagnosis is usually made by transthoracic or transesophageal echocardiography, cardiac catheterization with aortography, or MRI. Congenital sinus of Valsalva aneurysms is usually undetected until they rupture, which usually occurs in the third or fourth decade of life [5]. The risk of rupture is about 
$0.4 \%$ [6]. Closure of an aortic right ventricular fistula in asymptomatic patients is recommended due to the low rate of procedure related complications and the risk of heart failure, bacterial endocarditis, pulmonary vascular disease, aneurysm formation, and spontaneous rupture. Treatment options include surgery and, more recently, percutaneous closure; however the optimal management remains unclear. On the other hand, coronary artery fistulas are the most common hemodynamically significant congenital coronary abnormality. They account for $0.2-0.4 \%$ of all congenital cardiac anomalies. This anomaly may lead to heart failure, infectious endocarditis, and arrhythmia. Spontaneous closure is rare and surgical closure is usually required [7]. The patient, therefore, required and underwent surgical closure.

\section{Conflict of Interests}

The authors do not have a direct financial relation that might lead to a conflict of interests for any of them.

\section{References}

[1] J. H. Mayer III, T. M. Holder, and R. V. Canent, "Isolated, unruptured sinus of Valsalva aneurysm. Serendipitous detection and correction," Journal of Thoracic and Cardiovascular Surgery, vol. 69, no. 3, pp. 429-432, 1975.

[2] S.-H. Chu, C.-R. Hung, S.-S. How et al., "Ruptured aneurysms of the sinus of Valsalva in Oriental patients," Journal of Thoracic and Cardiovascular Surgery, vol. 99, no. 2, pp. 288-298, 1990.

[3] W. H. Heydorn, W. P. Nelson, J. D. Fitterer, G. D. Floyd, and T. E. Strevey, "Congenital aneurysm of the sinus of Valsalva protruding into the left ventricle. Review of diagnosis and treatment of the unruptured aneurysm," Journal of Thoracic and Cardiovascular Surgery, vol. 71, no. 6, pp. 839-845, 1976.

[4] T. J. Takach, G. J. Reul, J. M. Duncan et al., "Sinus of valsalva aneurysm or fistula: management and outcome," Annals of Thoracic Surgery, vol. 68, no. 5, pp. 1573-1577, 1999.

[5] P. Fazendas, C. Cotrim, F. Matias et al., "Fistula from the aortic sinus of valsalva to the right ventricle-case report," Revista Portuguesa de Cardiologia, vol. 21, no. 10, pp. 1167-1171, 2002.

[6] K. M. Babacan, O. Tasdemir, M. Zengin et al., "Fistulous communication of aortic sinuses into the cardiac chambers. Fifteen years surgical experience and a report of 23 patients," Japanese Heart Journal, vol. 27, no. 6, pp. 865-870, 1986.

[7] K. Stroeh, C. Schreiber, R. Henze, and R. Lange, "Surgical correction of a congenital coronary arterial fistula and a massive sinus of Valsalva aneurysm," Interactive Cardiovascular and Thoracic Surgery, vol. 15, pp. 907-908, 2012. 


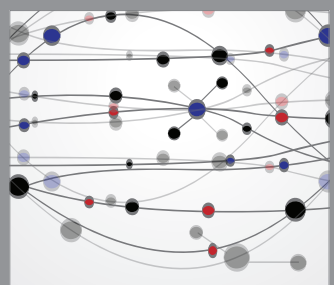

The Scientific World Journal
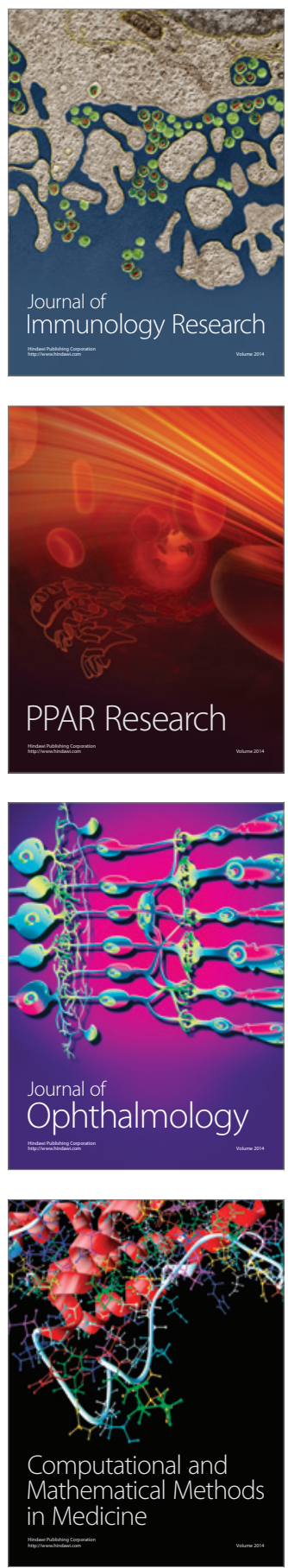

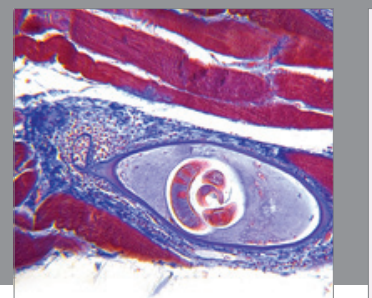

Gastroenterology

Research and Practice
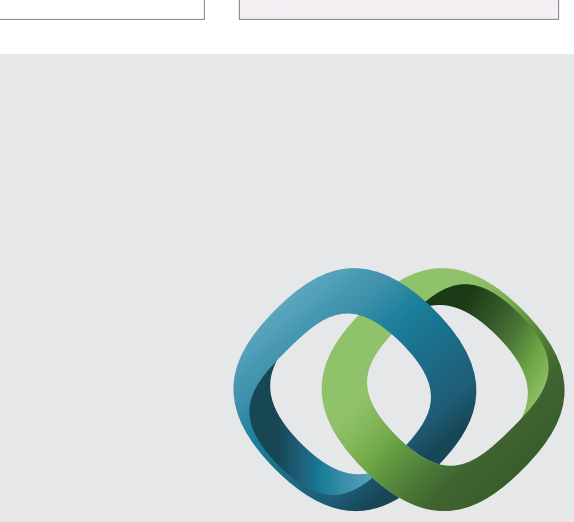

\section{Hindawi}

Submit your manuscripts at

http://www.hindawi.com
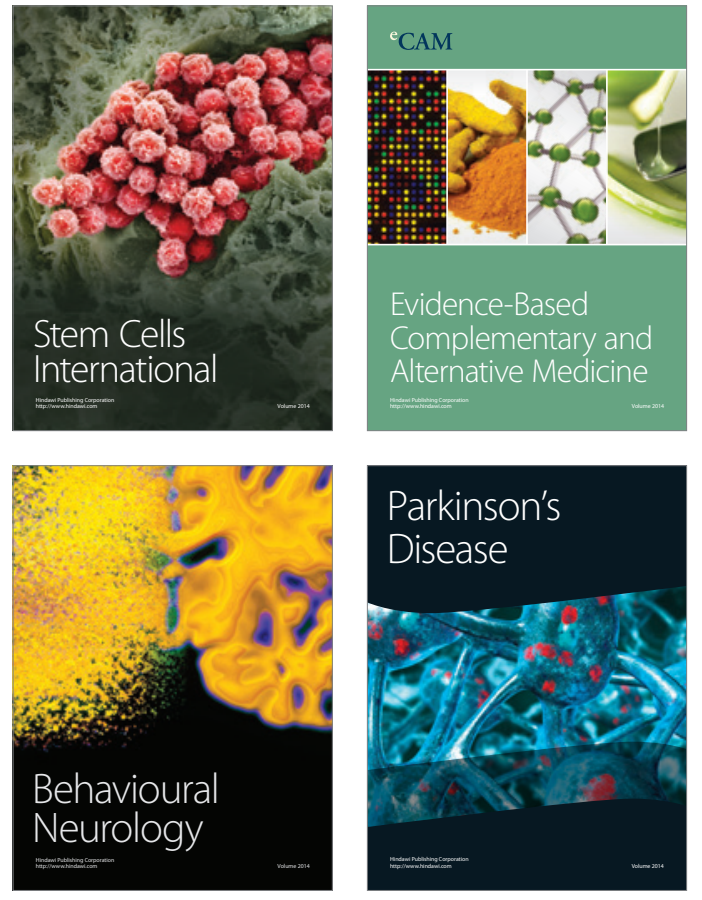
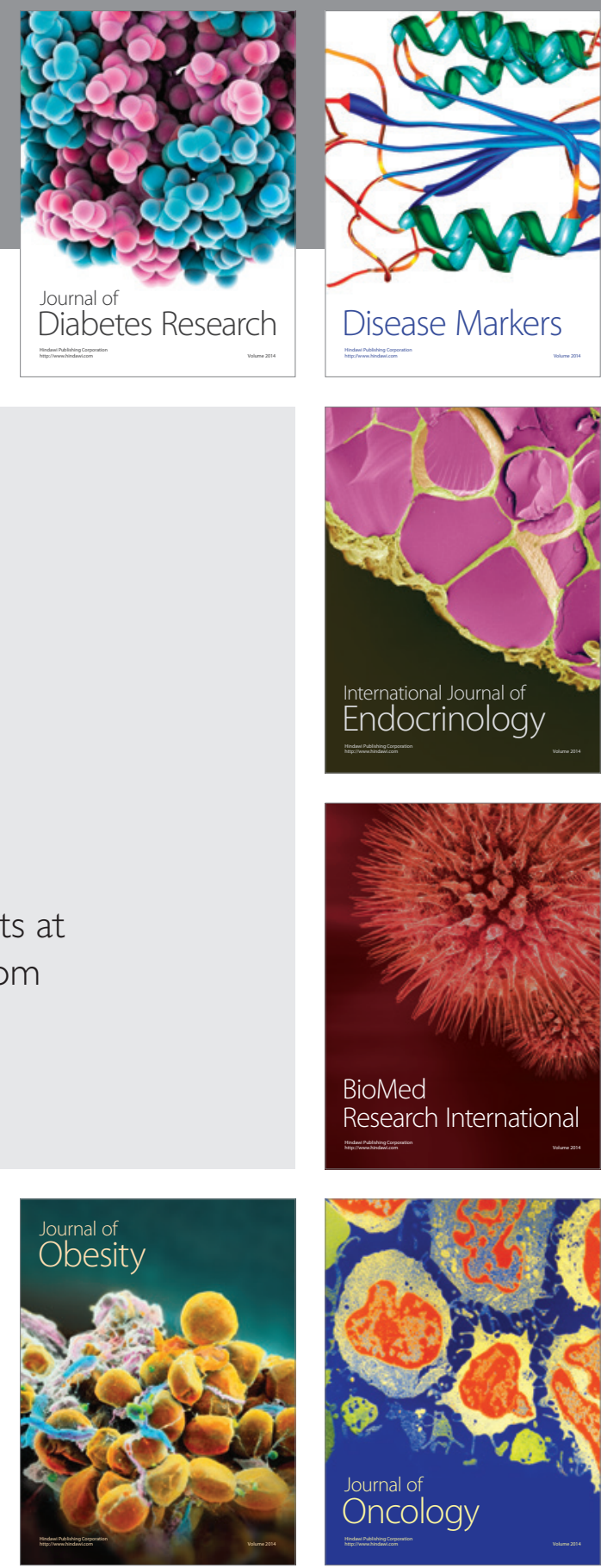

Disease Markers
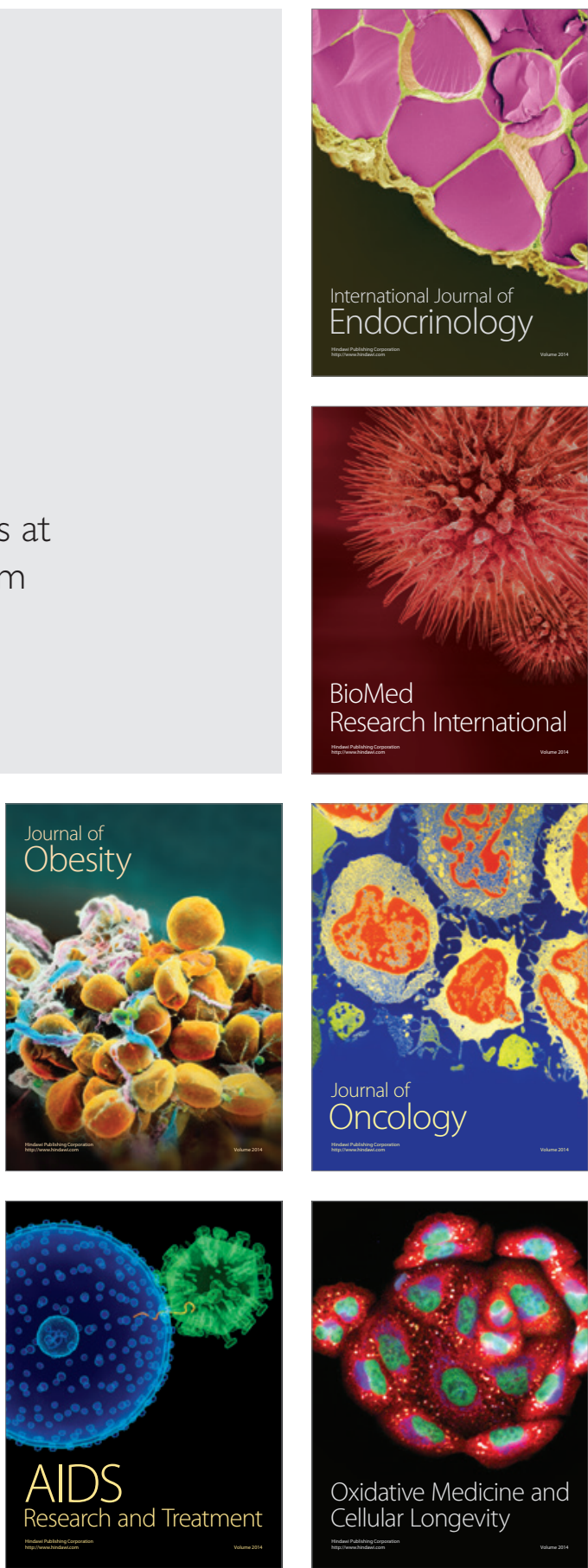